\title{
Effects of Kaixinjieyu, a Chinese herbal medicine preparation, on neurovascular unit dysfunction in rats with vascular depression
}

\author{
Juhua Pan ${ }^{1}$, Xiaoming Lei ${ }^{2}$, Jialong Wang ${ }^{1}$, Shijing Huang ${ }^{1 *}$, Yanyun Wang ${ }^{1}$, Ying Zhang ${ }^{1}$, Wen Chen ${ }^{1}$, Duojiao Li ${ }^{1}$, \\ Jun Zheng ${ }^{1}$, Hanming Cui ${ }^{1}$ and Qihua Liu ${ }^{1}$
}

\begin{abstract}
Background: Kaixinjieyu (KJ), derived from Kaixin and Sini powder, is an effective Chinese herbal medicine preparation used in the treatment of vascular depression (VD). We hypothesize that broad antidepressant effect of KJ results from the improved neurovascular unit (NVU) function via neurogenesis, permeability of blood-brain barrier (BBB) and balance of the fibrinolytic system.

Methods: A VD model of rat was established by chronic unpredictable mild stress and separation after ligation of the bilateral common carotid arteries. The rats were treated with $\mathrm{KJ}$ and fluoxetine hydrochloride (FLU) for 21 days, respectively. The behavior and cerebral perfusion were investigated and then NVU functions including neurogenesis, permeability of BBB and balance of the fibrinolytic system were studied using a number of biomarkers and TUNEL assay.
\end{abstract}

Results: KJ significantly increased sucrose preference, moving distance, number of rearing and cortical blood flow. NVU functions measured by brain-derived neurotrophic factor (BDNF), tropomyosin receptor kinase B (TrkB) and tissue plasminogen activator (t-PA) proteins and mRNA, zona occludens protein-1 (ZO-1), occludin and claudin-5 proteins increased significantly, whereas, plasminogen activator inhibitor-1 (PAI-1), matrix metalloproteinase-2 (MMP-2) proteins, mRNA and apoptotic rates of neurons decreased significantly with treatment of KJ. FLU has a function similar to KJ in behavior, regulation of BDNF, TrkB, MMP-2, occludin and apoptotic rates of cells.

Conclusions: $\mathrm{KJ}$ has function of reducing depression-like behavior and improving cerebral hypoperfusion, which might be mediated by the up-regulation of neurogenesis and tight junction of BBB, and balance of the fibrinolytic system. The results imply that $\mathrm{KJ}$ is better than FLU in improving cerebral hypoperfusion and the fibrinolytic system.

Keywords: Kaixinjieyu, Chinese herbal medicine, Vascular depression, Neurovascular unit, Blood-brain barrier, Neurogenesis

\section{Background}

Vascular depression (VD) is defined as a subtype of latelife depression associated with vascular diseases or cerebrovascular risk factors such as age, stroke, myocardial infarction, hypertension, hyperlipidemia and diabetes $[1$, 2]. Studies have shown that about $3.4 \%$ adults of 50 years and older suffer from VD. Among adults who meet the criteria for lifetime major depression, over one-in-

\footnotetext{
*Correspondence: gamhsj@126.com

'Guang'anmen Hospital, China Academy of Chinese Medical Sciences, Beijing 100053, China

Full list of author information is available at the end of the article
}

five are considered to have the VD subtype [3]. VD has three subtypes, namely, post-stroke depression, MRIdefined VD and depression with cerebrovascular disorder risk factors [4]. Their common pathology is chronic cerebral ischemia caused by cerebrovascular diseases [5]. The event of stressful life notably results in the occurrence of VD [6].

A number of associated diseases of VD means complicated therapeutic strategies [1, 7]. For VD patients, depressive syndrome is not the primary disease but can be considered as one of the clinical manifestations in the wide symptom spectrum of the cerebral small vessel 
diseases [7]. VD is poorly responsive to antidepressants and the therapeutic strategy is often significantly different from other depressions. Therefore, VD is a useful concept for clinical interventions [8]. White-matter hyper intensities in the left hemisphere [9], especially in the cingulum bundle adjacent to the hippocampus [10], global vascular risk [11], magnetic resonance imaging findings and neuropsychological assessment [12] have been used as predictors of poor response to antidepressants in VD patients.

Earlier studies have shown that monoamine and its receptors are likely to have antidepressant-like effects only at the beginning, and subsequently, it is neural plasticity that generates the long-lasting antidepressant effects [13]. The current hypothesis of depression points toward neuroplasticity-related malfunction in information processing within neural networks regulating mood $[14,15]$. Neural plasticity and neurogenesis have become one of the main targets of antidepressants. Gudmundsson et al. reported that elderly women with major depressive disorder exhibited higher cerebrospinal fluid /serum albumin ratios compared to women without depression which indicates that blood-brain barrier (BBB) hyperpermeability occurs in major depressive disorder [16]. Increasingly the $\mathrm{BBB}$, which is formed by endothelial cells, is no longer viewed as an isolated conception, but as a major component of an integrated neurovascular unit (NVU) [17]. The NVU consists of neurons, endothelial cells, pericytes and glia, which are tightly coupled to control cerebrovascular function. This structural and functional unit may have major roles in VD pathogenesis [18]. Restoration of NVU function is considered as one of the main therapeutic targets.

The previous research has shown that Kaixinjieyu (KJ), a Chinese herbal medicine preparation from Kaixin and Sini powder, is capable of enhancing vital Qi (Chinese words, meaning the function of body and the ability of health maintenance) and reducing depression; it could improve both cognitive and physical function of VD patients clinically [19]. KJ has antidepressant effects on behavior and production of monoamines such as the neurotransmitters serotonin and norepinephrine and serotonin receptor of chronic unpredictable mild stress (CUMS) in rats [19]. Moreover, the previous study has demonstrated that KJ can increase the expression of glial fibrillary acidic protein and brain-derived neurotrophic factor (BDNF) in the hippocampus in VD model [20]. However, the effect of KJ on the dysfunction of neurovascular unit in VD is still unclear, especially in the prefrontal cortex and hippocampus, which are central in the pathophysiology of mood disorders [14].

In the present study, the antidepressant effects and a number of biomarkers of NVU functions including neurogenesis, fibrinolytic system and permeability of
$\mathrm{BBB}$ were investigated in $\mathrm{KJ}$-treated $\mathrm{VD}$ rats, such as BNDF, tropomyosin receptor kinase B (TrkB), tissue plasminogen activator ( $t-\mathrm{PA}$ ), plasminogen activator inhibitor-1 (PAI-1), matrix metalloproteinase-2 (MMP2), matrix metalloproteinase-9 (MMP-9), zona occludens protein-1 (ZO-1), occludin and claudin-5 [21-23].

\section{Methods}

\section{Preparation and compositional analysis of $\mathrm{KJ}$}

$\mathrm{KJ}$ is a prescription originated from eight herbal plants including Bupleurum chinense DC. (Chai-Hu), Paeonia lactiflora Pall. (Chi-Shao), Morinda officinalis How (Ba-JiTian), Poria cocos (Schw.) Wolf (Fu-Ling), Panax ginseng C. A. Mey. (Ren-Shen), Citrus aurantium L.(Zhi-Shi), Polygala tenuifolia Willd. (Yuan-Zhi) and Glycyrrhiza uralensis Fisch. (Gan-Cao), in weight ratio of 3:3:3:3:2:2:2:2. These plant materials were bought from Beijing Bencao Fangyuan Pharmaceutical Co., Ltd (Beijing, China). Panax ginseng C. A. Mey. and Poria cocos (Schw.) Wolf were grinded into powder of less than 100 meshes in size. Other herbs were decocted twice, each for $1.5 \mathrm{~h}$. The filtrates were merged and concentrated to obtain a cream (relative density of $1.30-1.35 \mathrm{~g} / \mathrm{cm}^{3}$ at $55-60{ }^{\circ} \mathrm{C}$ ) by evaporation under reduced pressure. The preparation (KJ) was made up with the powder and cream by weight ratio of 1.2:1, and analyzed for composition by high performance liquid chromatography (HPLC).

The test solution was prepared by dissolving $\mathrm{KJ}$ in methanol, and analyzed on an Agilent 1200 HPLC (DAD) system with an C18 analytical column $(250 \times 4.6 \mathrm{~mm}$, $5 \mu \mathrm{m})$. The mobile phase was consisted of acetonitrile and water in gradient elution. For quality control, standards including ginsenosides $\mathrm{Rg}_{1}$, $\mathrm{Re}$ and $\mathrm{Rb}_{1}$ for Panax ginseng C. A. Mey., nistose for Morinda officinalis How,

Table 1 Primer pairs used for real-time PCR

\begin{tabular}{|c|c|c|c|}
\hline \multirow{2}{*}{$\frac{\text { Gene }}{\mathrm{MMP}-2}$} & \multicolumn{2}{|c|}{ Primer } & \multirow{2}{*}{$\begin{array}{l}\text { Product length (bp) } \\
237\end{array}$} \\
\hline & $F$ & 5'-ACACCCTCAAGAAGATGCAGA-3' & \\
\hline & R & 5'-ATACTITTAAGGCCCGAGCAA-3' & \\
\hline \multirow[t]{2}{*}{ MMP-9 } & $\mathrm{F}$ & 5'-TTTGGAAACGCAAATGGTG-3' & 210 \\
\hline & $\mathrm{R}$ & 5'-TGGAAATACGCAGGGTTTG-3' & \\
\hline \multirow[t]{2}{*}{ t-PA } & $\mathrm{F}$ & 5'-AGACATCACCTCACACCCTTG-3' & 194 \\
\hline & R & 5'-TTCCAGGGACCACTCTGTATG-3' & \\
\hline \multirow[t]{2}{*}{ PAl-1 } & $\mathrm{F}$ & 5'-GCCCCACTTCTTCAAGCTC-3' & 160 \\
\hline & $\mathrm{R}$ & 5'-CAGGCGTGTCAGCTCATTT-3' & \\
\hline \multirow[t]{2}{*}{ BDNF } & $\mathrm{F}$ & 5'-GCATCAGAAAAAGAGGCAAAC-3' & 194 \\
\hline & R & 5'-AGGCTACGTGAAGTCTTCCAA-3' & \\
\hline \multirow[t]{2}{*}{ TrkB } & F & 5'-GTCTGCTGAAGCCTGCATATC-3' & 191 \\
\hline & $\mathrm{R}$ & 5'-ATGAGTGCGTTGGAATGAAAC-3' & \\
\hline \multirow[t]{2}{*}{ GAPDH } & $\mathrm{F}$ & 5'-CCATGGAGAAGGCTGGG3' & 195 \\
\hline & $R$ & 5'-CAAAGTTGTCATGGATGACC-3' & \\
\hline
\end{tabular}


Table 2 The main bioactive compounds and composition analysis of $\mathrm{KJ}$

\begin{tabular}{llll}
\hline Origin of Herb & Compound & Formula & Content (mg/g) \\
\hline Morinda officinalis How & Nistose & $\mathrm{C}_{24} \mathrm{H}_{42} \mathrm{O}_{21}$ & 2.50 \\
Paeonia lactiflora Pall. & Paeoniflorin & $\mathrm{C}_{23} \mathrm{H}_{28} \mathrm{O}_{11}$ & 3.06 \\
Bupleurum chinense DC. & Saikosaponin A & $\mathrm{C}_{42} \mathrm{H}_{68} \mathrm{O}_{13}$ & 0.28 \\
Glycyrrhiza uralensis Fisch. & Saikosaponin D & $\mathrm{C}_{42} \mathrm{H}_{68} \mathrm{O}_{13}$ & 0.13 \\
& Glycyrrhizic acid Ammonium salt & $\mathrm{C}_{42} \mathrm{H}_{65} \mathrm{NO}_{16}$ & 0.95 \\
Citrus aurantium L. & Liquiritin & $\mathrm{C}_{21} \mathrm{H}_{22} \mathrm{O}_{9}$ & 0.52 \\
& Naringin & $\mathrm{C}_{27} \mathrm{H}_{32} \mathrm{O}_{14}$ & 3.72 \\
Panax ginseng C. A. Mey. & Neohesperidin & $\mathrm{C}_{28} \mathrm{H}_{34} \mathrm{O}_{15}$ & 1.06 \\
& Hesperidin & $\mathrm{C}_{28} \mathrm{H}_{34} \mathrm{O}_{15}$ & 15.24 \\
& Ginsenoside $\mathrm{Rg}$ & $\mathrm{C}_{42} \mathrm{H}_{72} \mathrm{O}_{14}$ & $\mathrm{C}_{48} \mathrm{H}_{82} \mathrm{O}_{18}$ \\
& Ginsenoside $\mathrm{Re}$ & $\mathrm{C}_{54} \mathrm{H}_{92} \mathrm{O}_{23}$ & 1.19 \\
\hline
\end{tabular}

paeoniflorin for Paeonia lactiflora Pall., saikosaponin A and D for Bupleurum chinense DC., Glycyrrhizic acid ammonium salt and liquiritin for Glycyrrhiza uralensis Fisch., naringin, neohesperidin and hesperidin for Citrus aurantium L. were used. All the standards were purchased from National Institutes for Food and Drug Control (Beijing, China).

\section{Animal, model and treatment}

Eighty male Sprague-Dawley rats $(250 \pm 10$ g, 7 weeks old), SPF grade, were purchased from Vital River Lab Animal Technology Co., Ltd (Beijing, China). All experiments were approved by the Ethical Committee of Guang'anmen Hospital, China Academy of Chinese Medical Sciences (Beijing, China). The animals were cared in accordance with the "Guide for the Care and Use of Laboratory Animals" of the National Institutes of Health. Rats were initially divided into two groups: sham-operated rats (sham group, $n=8$ ) were fed in a breeding box each with 4 rats normally and a permanent ligation of bilateral common carotid arteries (LBCCA) group $(n=72)$. The rats were anesthetized with intraperitoneal chloral hydrate $(350 \mathrm{mg} / \mathrm{kg})$. Through a midline cervical incision, the bilateral common carotid arteries were exposed and double ligated with silk sutures. The sham-operated rats were treated in a manner similar to that of the operated ones, except that the common carotid arteries were not occluded [24]. Forty-two survived rats were randomly divided into 5 groups for sucrose preference test (SPT) and fed individually in a box and received CUMS for 21 consecutive days from 7 days post LBCCA. Some were treated with KJ at dose of $1.8 \mathrm{~g} / \mathrm{kg} /$ day $(\mathrm{KJ}-\mathrm{H}, n=9), 0.9 \mathrm{~g} / \mathrm{kg} /$ day $(\mathrm{KJ}-\mathrm{M}, n=9)$, $0.45 \mathrm{~g} / \mathrm{kg} /$ day $(\mathrm{KJ}-\mathrm{L}, n=8)$ and fluoxetine hydrochloride at dose of $2.0 \mathrm{mg} / \mathrm{kg} /$ day (FLU, $n=8$ ). $\mathrm{KJ}$ and FLU were administered for 21 consecutive days from 7 days post LBCCA. The others were treated with nothing as VD model (VD, $n=8$ ) [20]. Mild stressors used included placing an empty bottle in cages for $1 \mathrm{~h}$, nipping the tail for $1 \mathrm{~min}$, swimming in $4{ }^{\circ} \mathrm{C}$ water for $5 \mathrm{~min}$, heating in $45{ }^{\circ} \mathrm{C}$ oven for $5 \mathrm{~min}$, inversion of the light/dark cycle for $24 \mathrm{~h}$, cage tilting for $24 \mathrm{~h}$, fasting for $24 \mathrm{~h}$, water deprivation for $24 \mathrm{~h}$, wet bedding for $24 \mathrm{~h}$, shaking for $3 \mathrm{~min}$ (160 rpm) and

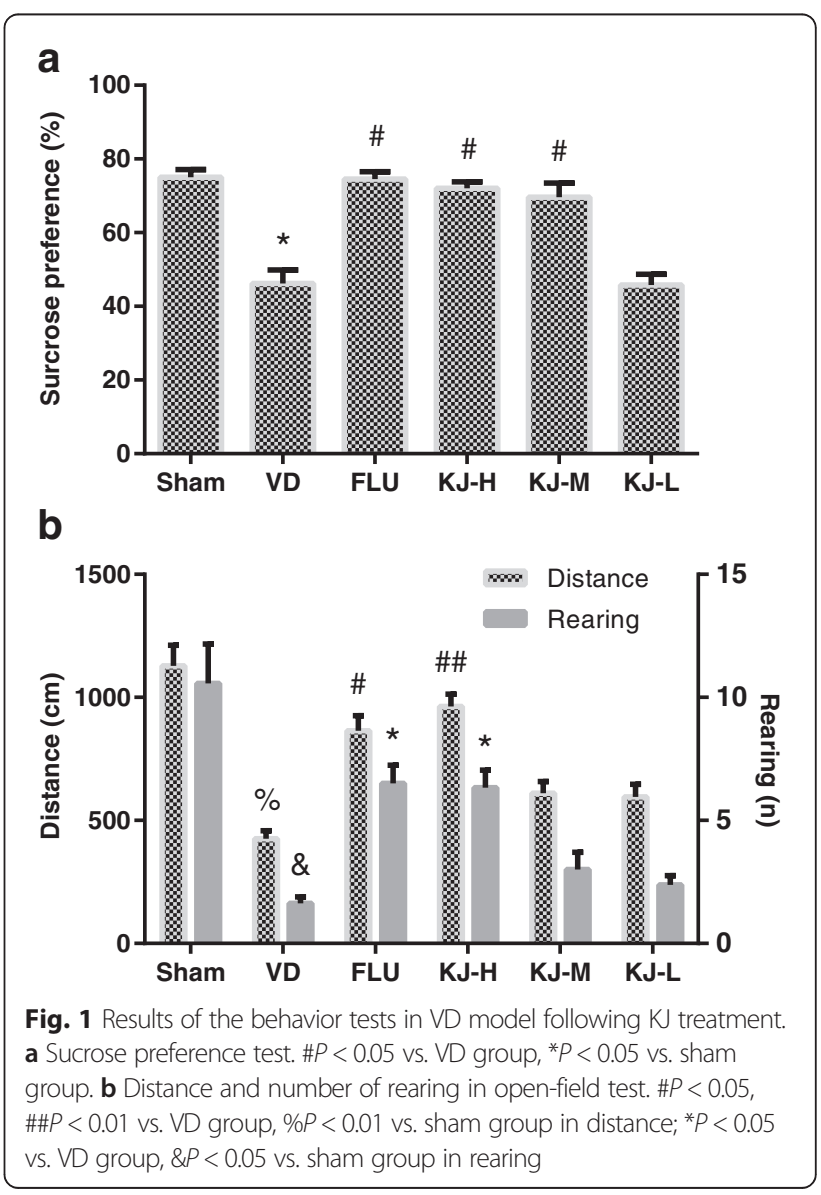


electric shock $(60 \mathrm{~V}, 1 \mathrm{~mA}$, lasting $10 \mathrm{~s}$ at an interval of 1 min, 5 times). Rats received one of these stressors per day, but the same stressor was not applied in two consecutive days.

\section{Behavior tests}

SPT and open-field test (OFT) were carried out after CUMS as described [25]. The consumptions of $1 \%$ sucrose solution and distilled water in $2 \mathrm{~h}$ were measured. The sucrose preference was calculated as the percentage of the sucrose solution consumed to the solution (sucrose solution and water) consumed. OFT was tested using the OFT-100 video analysis system. A rat was placed in the center of the box individually and recorded for its moving distance and the number of rearing.

\section{Cerebral perfusion}

All rats were anesthetized with $10 \%$ chloral hydrate (350 $\mathrm{mg} / \mathrm{kg}$ ) after the behavioral tests. Skin was removed and skull fully exposed. The cerebral perfusion was captured with a Perfusion Speckle Imager (Perimed AB, Sweden). Data were processed using PIMSoft and the means of cortical blood flow (CBF) in the left and right hemispheres were calculated.

\section{The terminal transferase dUTP nick end labeling (TUNEL) assay}

Rats were perfused alive with $4{ }^{\circ} \mathrm{C}$ normal saline and decollated. Right cerebral tissues were fixed in paraformaldehyde (40 g/L) overnight, embedded and sectioned. Sections were processed for the TUNEL assay using InSitu Cell-Death Detection (POD) kit, (Roche, Penzberg, Germany) according to the manufacturer's instructions

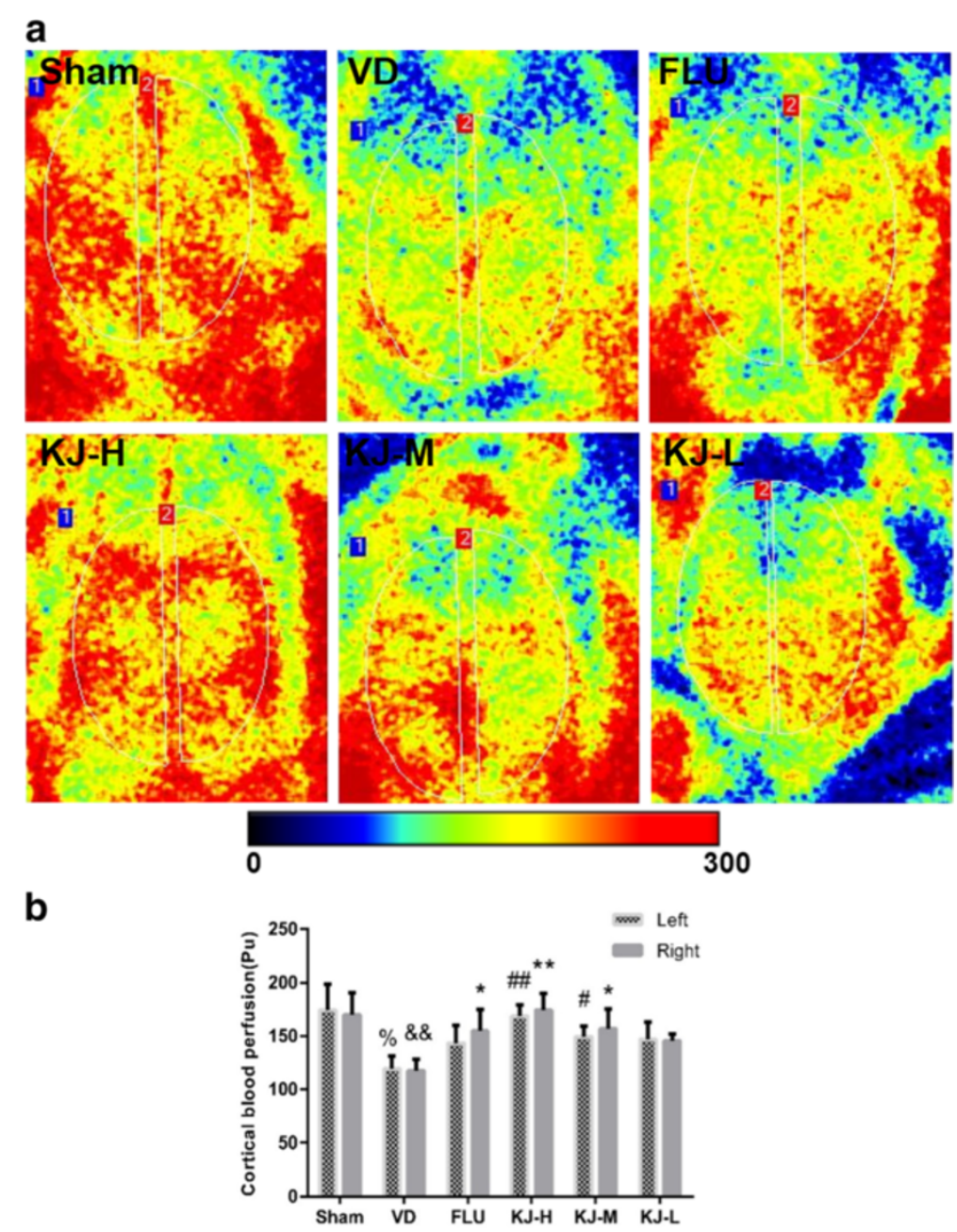

Fig. 2 Cortical blood flow in VD model following $\mathrm{KJ}$ treatment. a the microcirculation imaging of cerebrum. The white line-encircled area is the region of interest. VD rats display a decreased trend of the cortical blood flow (CBF) compared with the sham group. Rats in KJ-H, KJ-M and FLU groups display a notable increase of the CBF. $\mathbf{b}$ CBF of left and right hemisphere. Pu is a unit of cortical blood flow. \#P $<0.05$, \#\#P<0.01 vs. VD group; $\% P<0.01$ vs. sham group in the left hemisphere; ${ }^{*} P<0.05$, ${ }^{*} P<0.01$ vs. VD group; \&\&P<0.01 vs. sham group in the right hemisphere 
to reveal the degree of apoptosis in cerebral tissues. The investigators were blinded to the animal grouping. For each rat, four photographs were randomly selected. The apoptotic rate was obtained by counting the TUNEL positive cells compared to all the visible cells. A mean value was calculated from four values and the final values were subjected to statistical analysis.

\section{Immunohistochemical analysis}

Immunohistochemistry (IHC) was carried out with antibodies against BDNF (1:80, Abcam, Cambridge, MA, USA), TrkB (1:100, Abcam, Cambridge, MA, USA), t-PA (H-90) (1:200, Santa Cruz, CA, USA), PAI-1 (H-135) (1:200, Santa Cruz, CA, USA), MMP-2 (8B4) (1:200, Santa Cruz, CA, USA) and MMP-9 (C-20) (1:200, Santa Cruz, CA, USA). The proteins were quantified by integral optical density (IOD) with Image Pro Plus 6.0. For each rat, four sections were used to calculate the means.

\section{Real-time PCR analysis}

Determination of $B D N F$ and $\operatorname{Trk} B$ mRNA was carried out in the hippocampus, $t-P A, P A I-1, M M P-2$ and
MMP-9 mRNA were analyzed in the prefrontal cortex tissue by real-time PCR. Total RNA was extracted using Trizol reagent (Invitrogen, USA) according to the manufacturer's instructions. Then reverse transcription and real-time PCR reactions were performed with Revert Aid $^{\text {mu }}$ first strand cDNA synthesis kit (MBI, USA) and SYBR $^{\circ}$ Green PCR Master Mix (ABI, USA), respectively. The primers were designed with primer 3 web based on published rat cDNA sequences (Table 1). All primers were purchased from SBS Genetech Co., Ltd. (Beijing, China). Quantification of mRNA levels relative to GAPDH (a housekeeping gene) was made with the $2^{-}$ ${ }_{\triangle \triangle C T}$ method.

\section{Western blot analysis}

Prefrontal cortex tissues were washed and then lysed on cold RIPA buffer (50 mM Tris- $\mathrm{HCl} \mathrm{pH} 7.4,150 \mathrm{mM}$ $\mathrm{NaCl}, 1 \%$ TritonX-100, 1 \% sodium deoxycholate, and $0.1 \%$ SDS) containing a protease inhibitor cocktail (Roche, Penzberg, Germany). The protein concentration of each homogenate was determined using a BCA kit. Twenty-four $\mu \mathrm{g}$ of soluble protein was subjected to

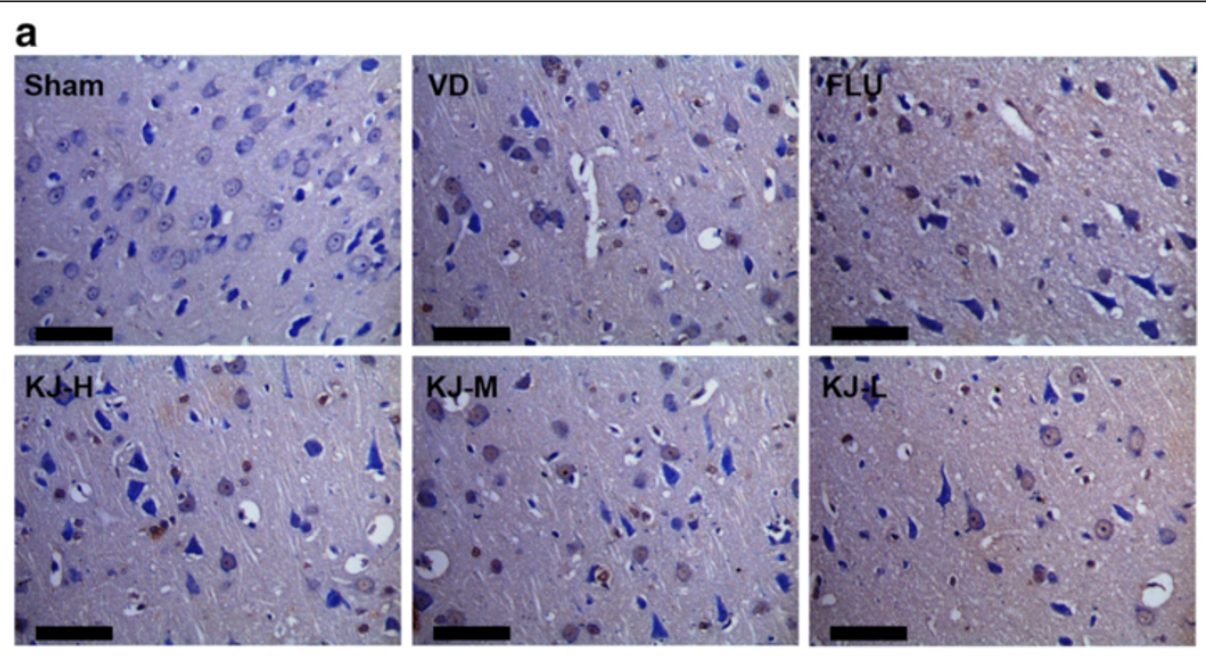

b

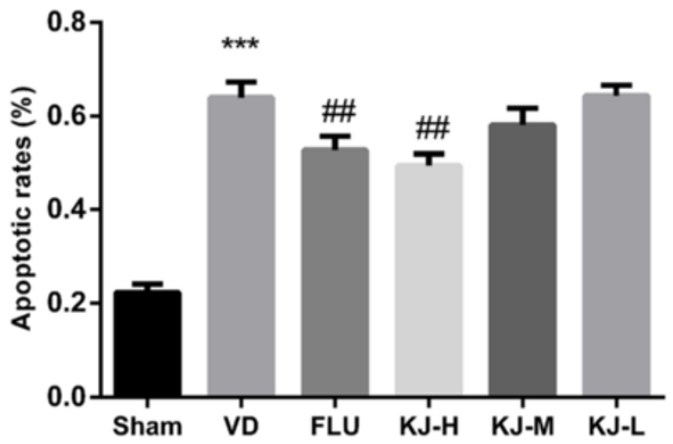

Fig. 3 TUNEL assay for analysis of apoptotic cells in brain tissues. a TUNEL assay of brain tissues. Cells with shrunken brown stained nuclei were considered positive. The TUNEL-positive cells were mainly observed in cortex. Scale bar: $50 \mu \mathrm{m}$. b Quantitative analysis of TUNEL-positive cells. $\# \#<0.01$ vs. VD group; ${ }^{* * *} P<0.001$ vs. sham group 
SDS-PAGE and electro-transferred onto PVDF membranes, which were then immunostained with the following primary antibodies against ZO-1 (1:1000, Thermo Fisher, Rockford, IL, USA), occludin (1:2000, Abcam, Cambridge, MA, USA), claudin-5 (1:1000, Thermo Fisher, Rockford, IL, USA), and $\beta$-actin (1:1000, Sigma, St Louis, $\mathrm{MO})$. The membranes were incubated with horseradish peroxidase-conjugated secondary antibodies. Immunoreactive proteins were detected by an enhanced chemiluminescence system.

\section{Data analysis}

The SPSS 16.0 (SPSS Inc., USA) software was used for the analysis. Data were expressed as mean \pm standard error. The data were statistically evaluated by one-way analysis of variance, and a post hoc analysis was performed by the Fisher's least significant difference test. $P$ $<0.05$ was regarded as statistically significant.

\section{Results}

\section{Composition of KJ preparation}

As shown in Table 2, twelve compounds from the herbs were identified and the content of each compound was in the range of 0.13 to $15.24 \mathrm{mg} / \mathrm{g}$. The contents of hesperidin, naringin, paeoniflorin and nistose were relatively higher among the identified compounds.

\section{Behavior test}

SPT and OFT were carried out to investigate the depression-like behavior. VD rats displayed a decreased sucrose preference compared with the sham group $(P<0.05)$; rats in $\mathrm{KJ}-\mathrm{H}, \mathrm{KJ}-\mathrm{M}$ and FLU groups had significant increases in sucrose preference compared with the VD group $(P<0.05$, Fig. 1a). In OFT, VD rats showed a decreased moving distance $(P<0.01)$ and the number of rearing $(P<0.05)$ compared with the sham group; rats in $\mathrm{KJ}-\mathrm{H}$ and FLU groups had significant increases in the moving distance $(P<0.01$, $P<0.05)$ and number of rearing $(P<0.05)$ compared with the VD group (Fig. 1b).

\section{Cerebral perfusion}

The CBF was reduced in VD rats compared with the sham rats $(P<0.01)$; rats in $\mathrm{KJ}-\mathrm{H}$ and $\mathrm{KJ}-\mathrm{M}$ groups displayed significant increase in the $\mathrm{CBF}$ compared with the VD group $(P<0.01, P<0.05$, respectively, Fig. 2$)$.
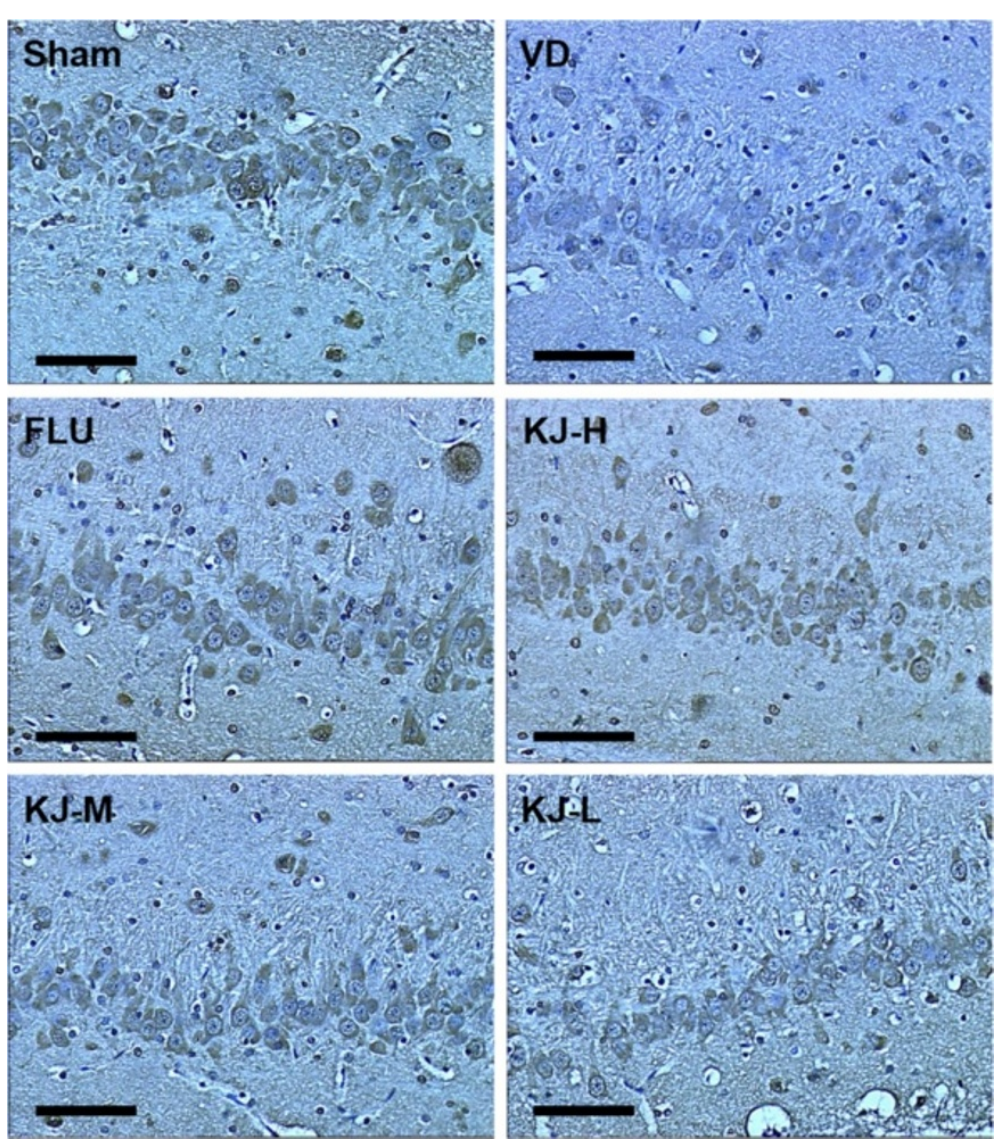

Fig. $4 \mathrm{HC}$ of BDNF protein in the hippocampus. BDNF is mainly expressed in the cytoplasm of neurons and glial cells as yellow or yellow-brown colored staining. More positive-staining cells are in the sham, FLU and KJ-H groups relatively. Scale bar: $50 \mu \mathrm{m}$ 


\section{TUNEL assay}

The TUNEL-positive cells were mainly observed in cortex but fewer in hippocampus. More cells were apoptotic in VD rats compared with the sham rats $(P<0.001)$; rats in $\mathrm{KJ}-\mathrm{H}$ and FLU groups displayed significant decrease in apoptotic rates compared with the VD group $(P<0.01$, Fig. 3).

\section{Protein and mRNA of BDNF and TrkB}

IHC-staining showed that BDNF and $\operatorname{TrkB}$ were mainly expressed in cytoplasm of neurons and glial cells as yellow or yellow-brown colored staining. BDNF and TrkB in the positive-cells were mainly located in the cytoplasm. The IOD of BDNF and TrkB positive-cells decreased significantly in the VD group compared with the sham group $(P<0.05)$. Compared with VD group, IOD of BDNF and TrkB positivecells increased significantly in FLU and $\mathrm{KJ}-\mathrm{H}$ groups $(P<0.05$, Figs. 4, 5, 6a and $c)$.

The levels of $B D N F$ and $\operatorname{Trk} B$ mRNA decreased significantly in the VD group $(P<0.05, P<0.01$, Fig. $6 \mathrm{~b}, \mathrm{~d})$ compared with the sham group. Whereas, compared with VD group, the levels of BDNF mRNA increased significantly in
KJ-H, KJ-M and FLU groups $(P<0.05$ or $P<0.01$, Fig. $6 \mathrm{~b})$, TrkB mRNA increased significantly in $\mathrm{KJ}-\mathrm{H}, \mathrm{KJ}-\mathrm{M}$ and $\mathrm{KJ}-$ L groups $(P<0.05$ or $P<0.01$, Fig. $6 \mathrm{~d})$.

\section{Protein and mRNA levels of t-PA, PAI-1, MMP-2 and MMP-9}

In IHC-stained slices, t-PA, PAI-1, MMP-2 and MMP-9 were expressed mainly in cytoplasm and a little in nucleus of neurons and glial cells as yellow or yellow-brown staining. T-PA and PAI-1 were also slightly expressed in the cytoplasm of endothelial cells. The IOD of t-PA positive-cells decreased significantly, PAI-1 and MMP-2 positive-cells increased significantly in the VD group compared with the sham group ( $P<0.05$ or $P<0.01$, Figs. $7,8,9,10$ a, c and e). IOD of t-PA positive-cells increased significantly in $\mathrm{KJ}-\mathrm{H}$ and FLU groups compared with the VD group $(P<0.05$, Figs. 7 and 10a); IOD of PAI-1 positive-cells decreased significantly in $\mathrm{KJ}-\mathrm{H}$ group $(P<0.05$, Figs. 8 and $10 \mathrm{c})$; IOD of MMP-2 positive cells decreased significantly in $\mathrm{KJ}-\mathrm{H}, \mathrm{KJ}-$ $\mathrm{M}$ and FLU groups $(P<0.05$, Figs. 9 and 10e). There was no significant difference in IOD of MMP-9 positive-cells among all groups.
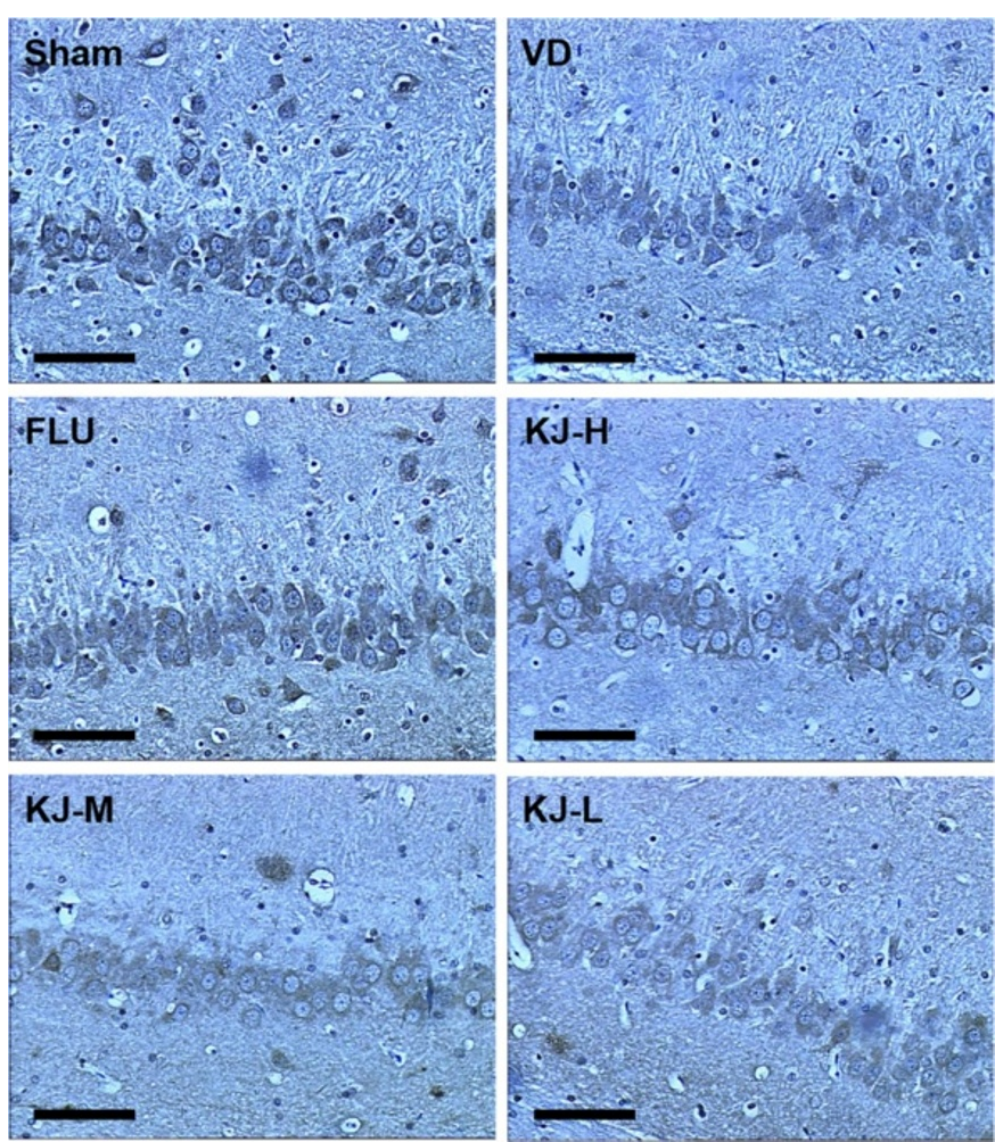

Fig. $5 \mathrm{IHC}$ of TrkB protein in the hippocampus. TrkB is mainly expressed in the cytoplasm of neurons and glial cells as yellow or yellow-brown colored staining. More positive-staining cells are in the sham, FLU and KJ-H groups relatively. Scale bar: $50 \mu \mathrm{m}$ 

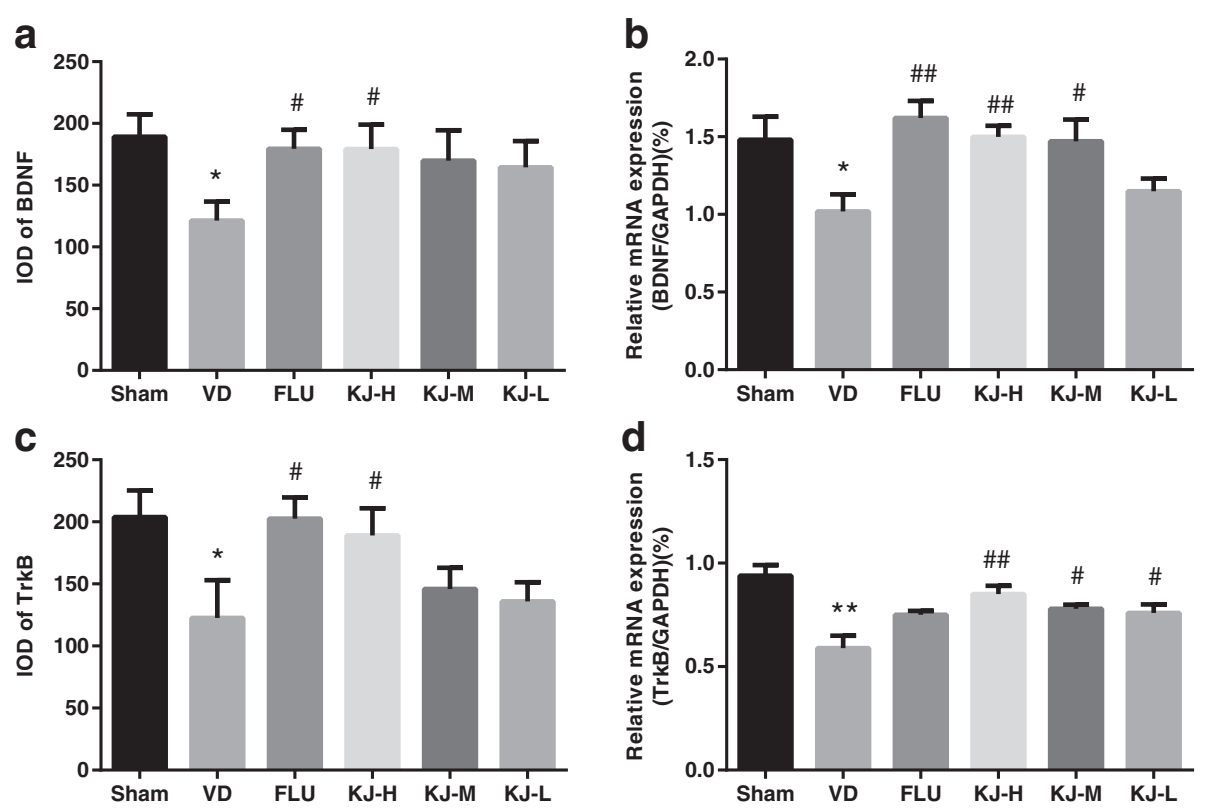

Fig. $\mathbf{6}$ The levels of BDNF and TrkB proteins and mRNA in the hippocampus. a IOD of BDNF by IHC. $\mathbf{b}$ BDNF mRNA levels by real-time PCR. $\mathbf{c}$ IOD of TrkB by IHC. d TrkB mRNA levels by real-time PCR. \#P<0.05, \#\#P<0.01 vs. VD group; ${ }^{* *} P<0.01$ vs. sham group
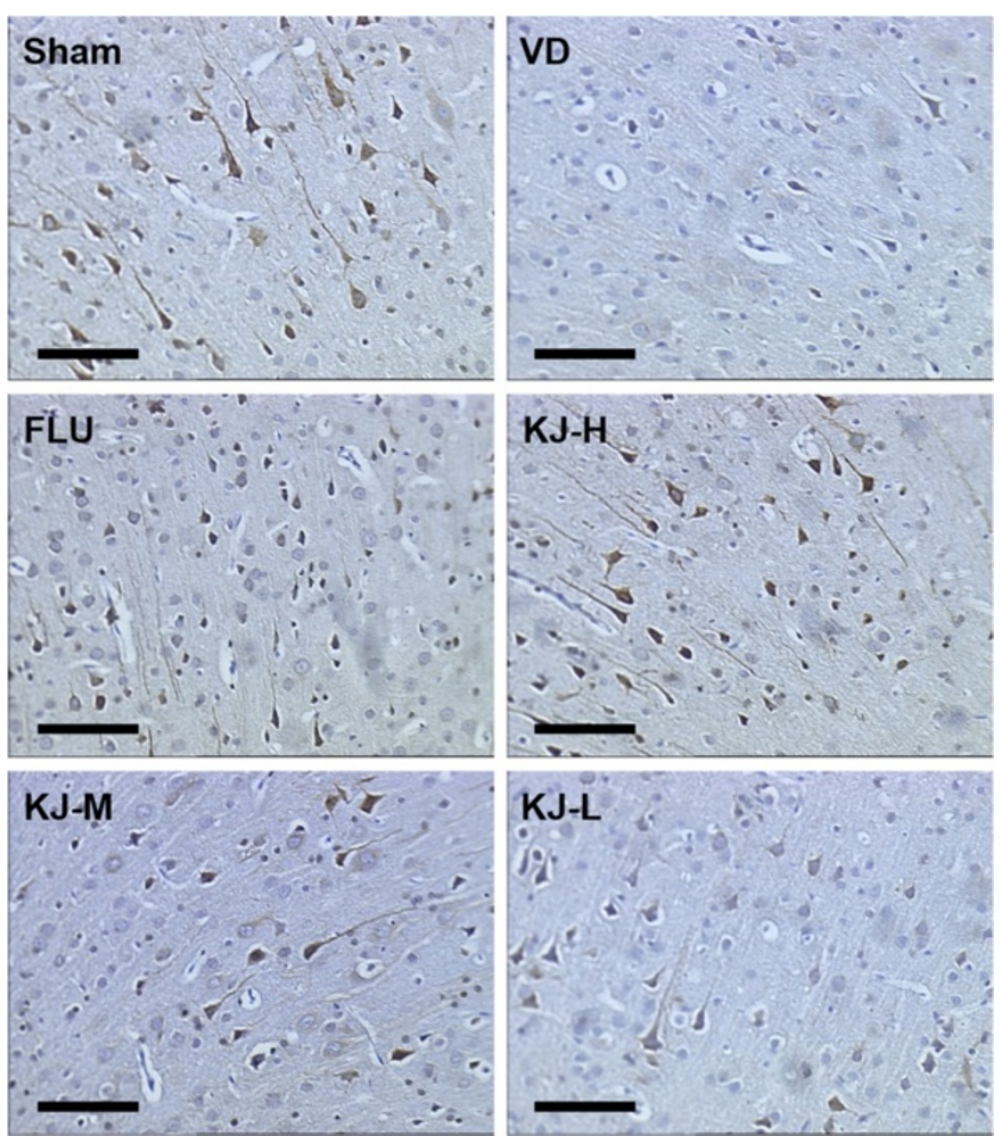

Fig. $7 \mathrm{HC}$ of t-PA protein in the cerebrum. T-PA is expressed mainly in the cytoplasm and a little in the nucleus of neurons and glial cells as yellow or yellow-brown colored staining. More positive-staining cells are in the sham, FLU and KJ-H groups relatively. Scale bar: $50 \mu \mathrm{m}$ 

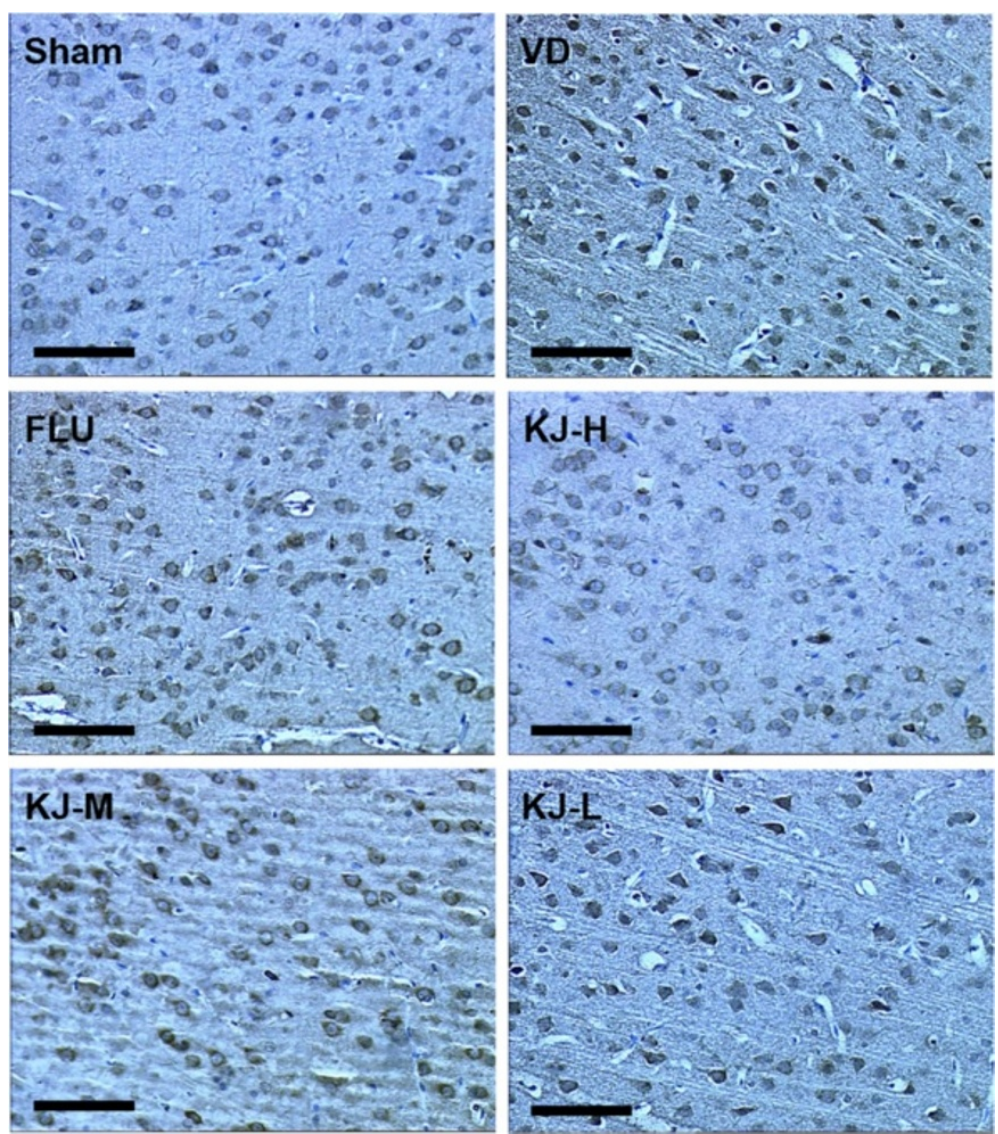

Fig. $8 \mathrm{HC}$ of PAl-1 protein in the cerebrum. PAl-1 is expressed mainly in the cytoplasm and a little in the nucleus of neurons and glial cells as yellow or yellow-brown colored staining. Less positive-staining cells are in the sham and KJ-H groups relatively. Scale bar: $50 \mu \mathrm{m}$

Compared with the sham group, $t-P A$ mRNA decreased significantly $(P<0.05), P A I-1$ and $M M P-2$ mRNA increased significantly $(P<0.05, P<0.01)$ in the VD group (Fig. 10b, $\mathrm{d}$ and $\mathrm{f}$ ). Levels of $t-P A$ mRNA increased and $P A I-1$ mRNA decreased significantly in $\mathrm{KJ}-\mathrm{H}$ group compared with the VD group $(P<0.05)$ (Fig. 10b, d). $M M P-2$ mRNA levels decreased significantly in $\mathrm{KJ}-\mathrm{H}, \mathrm{KJ}-\mathrm{M}$ and FLU groups $(P<0.05$ or $P<0.01)$ (Fig. 10f). There was no significant difference in $M M P-9$ mRNA levels among all groups.

\section{Levels of ZO-1, occludin and claudin-5}

As shown in Fig. 11a, the expression of tight junction biomarkers including ZO- 1 , occludin and claudin-5 was significantly decreased in the VD group compared with sham group $(P<0.01$ or $P<0.001)$. The expression of $\mathrm{ZO}-1$ increased significantly in $\mathrm{KJ}-\mathrm{H}$ group compared with VD group $(P<0.05$, Fig. 11b). The expression of occludin increased significantly in $\mathrm{KJ}-\mathrm{H}, \mathrm{KJ}-\mathrm{M}$ and FLU groups compared with VD group $(P<0.001, P<0.05, \quad P$ $<0.01$, Fig. 11c). The expression of claudin-5 increased significantly in $\mathrm{KJ}-\mathrm{H}$ group compared with $\mathrm{VD}$ group $(P<0.05$, Fig. 11d).

\section{Discussion}

Effects of KJ on depression-like behavior and cerebral perfusion

A number of rat VD models have been established, such as those resulted from aging [26], high-fat feeding and CUMS [27], individual feeding in a box post LBCCA and treated with CUMS [20]. The VD model established by feeding the rats individually after LBCCA and in combination with CUMS is considered to be ideal in simulating the common pathology (chronic cerebral hypoperfusion caused by cerebrovascular disease) [20]. In the present study, the VD models were evaluated by SPT, OFT and cerebral blood flow. The rats showed increased behavioral obstacles and significantly reduced cerebral perfusion after modelling, indicating that the model was successful in mimicking the core VD symptoms, such as anhedonia, declined athletic activity and reduced curiosity and cerebral perfusion. However, the findings of the present study i.e. the CBF in the VD rats decreased significantly 28 days post LBCCA are different from earlier studies [28, 29], which reported that the perfusion drops sharply immediately after occlusion [28], persists for several days after permanent LBCCA [29]. 

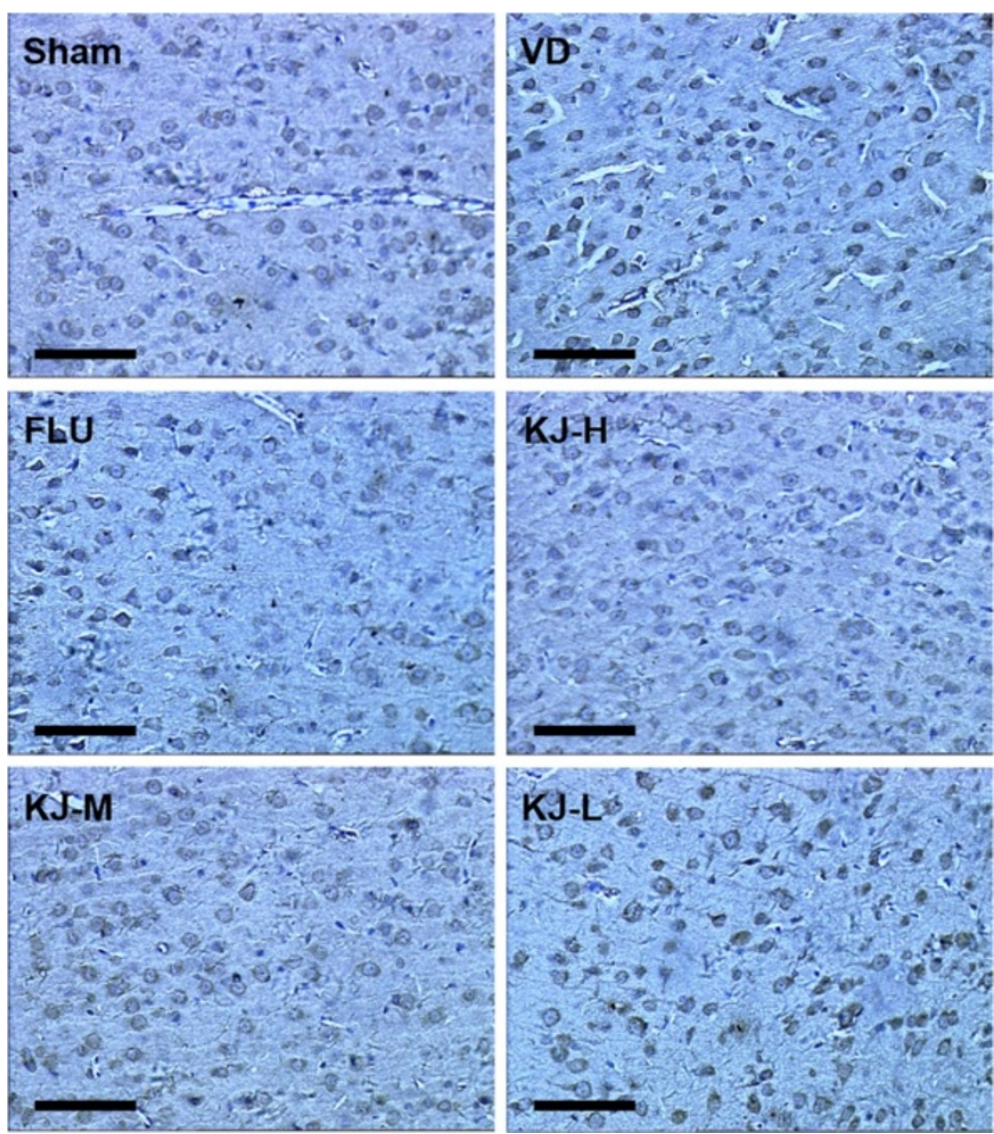

Fig. $9 \mathrm{IHC}$ of MMP-2 protein in the cerebrum. MMP-2 is expressed mainly in the cytoplasm and a little in the nucleus of neurons and glial cells as yellow or yellow-brown colored staining. More positive-staining cells are in the VD and KJ-L groups relatively. Scale bar: $50 \mu \mathrm{m}$

The compensatory redistribution via the vertebrobasilar network progressively restores the blood flow in almost all brain regions, and the cerebral blood perfusion is indistinguishable from controls after 1 month [28, 29]. The inconsistency suggests that CUMS might increase the duration of cerebral hypoperfusion, and further study is needed to clarify this.

The data demonstrate that that $\mathrm{KJ}$ at high and medium doses and FLU have similar antidepressant effects in terms of sucrose preference, moving distance and number of rearing. Furthermore, KJ, particularly at high dose, could improve the cerebral hypoperfusion better than FLU, suggesting it might be a better antidepressant option. The analysis shows that hesperidin $\left(\mathrm{C}_{28} \mathrm{H}_{34} \mathrm{O}_{15}\right)$ from Citrus aurantium $\mathrm{L}$. is the bioactive compound of the highest-content in KJ preparation. It has been shown to be able to penetrate the BBB [30] and prevent the neurodegeneration caused by conditions such as ischemia/reperfusion and promote healthy brain functions [31]. Therefore, Citrus aurantium L. might play a key role in improving the cerebral hypoperfusion and alleviating the depression. Since a number of compounds have been identified in the preparation, more works are needed to elucidate their roles in antidepressant effects.

\section{Mechanism of $\mathrm{KJ}$ on restoration of NVU function}

Chronic cerebral hypoperfusion induced by LBCCA is shown to result in hypoxia and ischemia in the brain, leading to impaired $\mathrm{BBB}$ [32]. A number of studies have shown that impaired BBB is often associated with depression [33, 34]. Recent studies have shown that oxidative stress and neuro inflammation in depression patients could cause BBB hyperpermeability and NVU dysfunction [17]. To better understand the mechanism of KJ effect on NVU, a number of biomarkers related to neurogenesis, fibrinolytic system and permeability of BBB were investigated at transcriptional and (or) translation levels.

Neurotrophins play important roles in neuron survival, plasticity, neurogenesis and synaptogenesis. BDNF as one of neurotrophins is shown to regulate the neurogenesis in adult hippocampus and generation of 5-hydroxy tryptophan, $\gamma$-aminobutyric acid and dopamine in central nervous system, and is involved in the plasticity of neurons [35]. Binding of BDNF to its high-affinity 

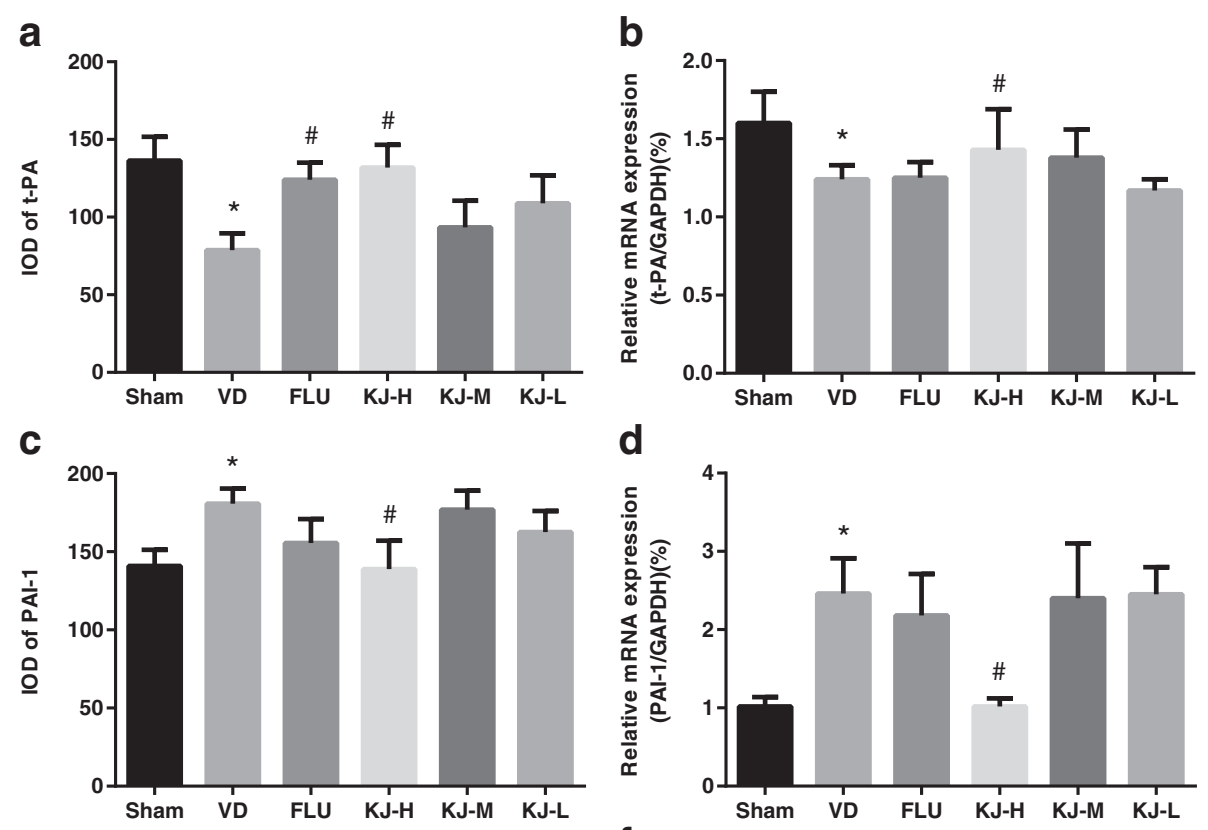

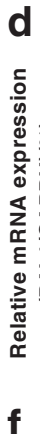
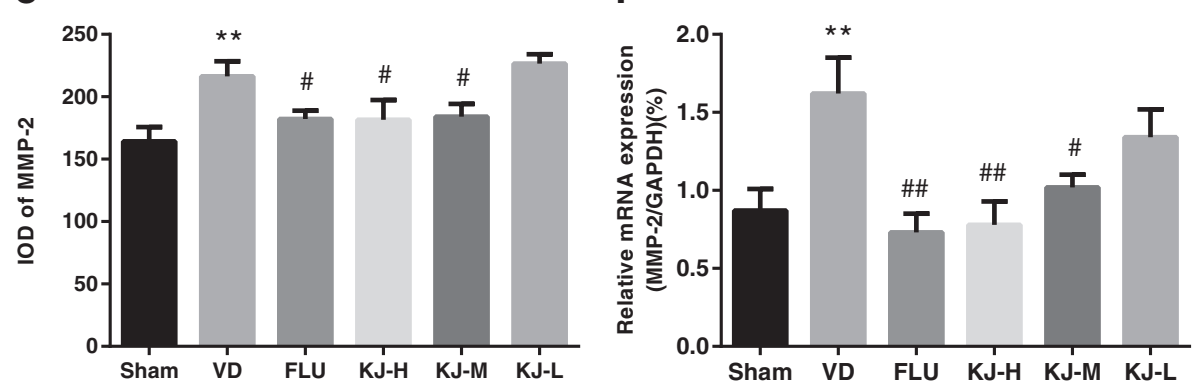

Fig. 10 The levels of T-PA, PAl-1and MMP-2 proteins and mRNA in the prefrontal cortex. $\mathbf{a}, \mathbf{c}, \mathbf{e}$ IOD of t-PA, PAl-1and MMP-2 by IHC. b, d, f T-PA, PAl-1 and MMP-2 mRNA levels by real-time PCR. \#P<0.05, \#\#P<0.01 vs. VD group; ${ }^{*} P<0.05$, ${ }^{*} P<0.01$ vs. sham group

receptor TrkB is found to activate MAPK, PI3-K and CaMK signal pathways, and cAMP response element binding protein and improve the survival and plasticity of neurons [36, 37]. The results show that KJ treatment up-regulates the expression of BDNF and TrkB at translational and transcriptional level and down- regulates the apoptotic rates of neurons in the VD model, suggesting that the antidepressant-like effects of KJ might be attributed to the neurogenesis in the cerebrum.

The $\mathrm{t}-\mathrm{PA} /$ plasminogen proteolytic cascade is known to be important for thrombolysis [38]. PAI-1 is the major inhibitor for t-PA [39]. Study shows that women with major depressive disorder have higher PAI-1 levels than normal controls [40], and PAI-1 gene variants may play a role in major depressive disorder susceptibility and in the acute therapeutic response to selective serotonin reuptake inhibitors [41]. In addition, PAI-1 could reduce the conversion of plasminogen into plasmin, reduce the cleavage of pro-BDNF to mature BDNF and weaken the protection of nerve by BDNF [42]. This study shows that
t-PA in VD rat declines, while PAI-1 increases, resulting in unbalanced fibrinolytic system. KJ could partially restore the fibrinolytic system, which might contribute to improved cerebral perfusion.

The BBB is a tightly sealed barrier between the circulating blood and the central nervous system, consisting of brain microvascular endothelial cells which are characterized by the presence of tight junctions (TJs) and lack of fenestrae, then confer the low paracellular permeability of BBB $[43,44]$. The main structural barrier proteins are occludin, zona occludens (ZO)-1 and claudin-5, and these are considered to be sensitive indicators of normal versus disturbed functional states of the BBB [45]. Yet, MMPs have the function of disrupting endothelial junction proteins in $\mathrm{BBB}$ in vitro and increase BBB opening [46, 47]. Nakaji [48] reported that MMP-2 was associated with BBB permeability and increases the migration of neutrophil and inflammation factors, resulting in damage in the limbic system. Earlier study shows that MMP-9 mediates the damage during 


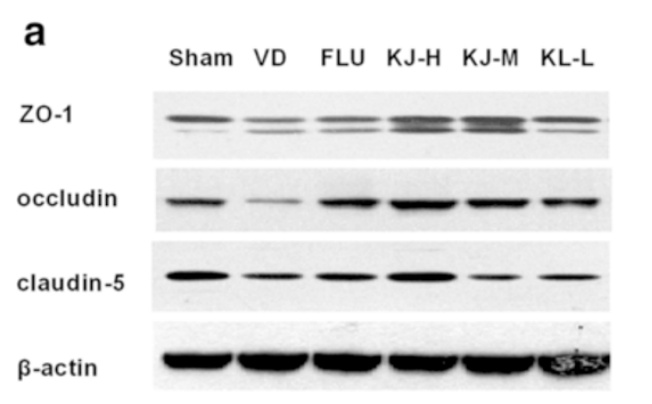

\section{C}

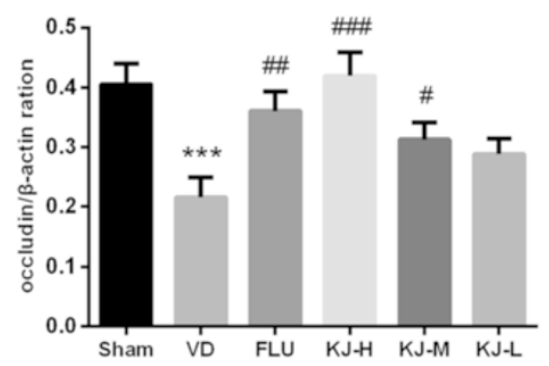

b

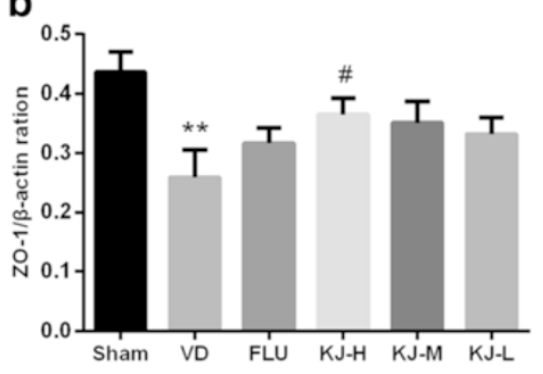

d

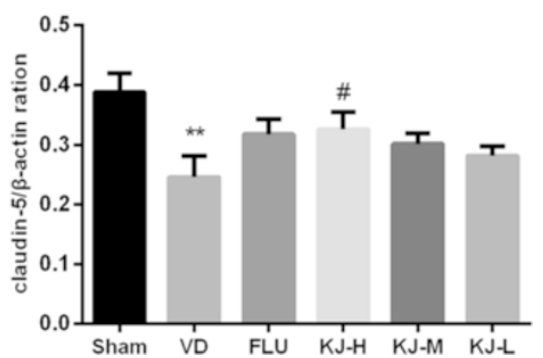

Fig. 11 The expression of ZO-1, occludin and claudin-5 proteins in the prefrontal cortex. a The expression of ZO-1, occludin and claudin-5 proteins was detected in the prefrontal cortex of VD rats by Western Blot. $\beta$-actin was used as a loading control. Relative folds of ZO-1 (b), occluding (c) and claudin-5 (d) were calculated by normalization to $\beta$-actin. $\# P<0.05$, \#\# $<0.01$, \#\#\#P<0.001 vs. VD group; ${ }^{* *} P<0.01$, ${ }^{* * *} P<0.001$ vs. sham group

ischemia/reperfusion and activation of it occurred at 12, 24 and $48 \mathrm{~h}$ after reperfusion [49]. The results show that there is no obvious difference in MMP-9 in the VD rats, which might be because the MMP-9 is mainly involved in the acute phase but not in the chronic phase of cerebral hypoperfusion. The up-regulated levels of MMP-2 protein and mRNA, down-regulated levels of $\mathrm{ZO}-1$, occludin and claudin-5 in the VD rats are partially returned to the normal levels as in the sham group with treatment of $\mathrm{KJ}$. The normalization might reduce the $\mathrm{BBB}$ hyperpermeability and inflammation in the VD rats. It might also be responsible for the antidepressant effects of $\mathrm{KJ}$.

\section{Conclusions}

The present study indicated that $\mathrm{KJ}$ could reduce depression-like behavior and improve chronic cerebral hypoperfusion in VD rats. The effects might be mediated by the up-regulation of neurogenesis and tight junction of $\mathrm{BBB}$, and balance of the fibrinolytic system, which result in restoration of NVU function. The results imply that $\mathrm{KJ}$ is better than FLU in improving cerebral hypoperfusion and the fibrinolytic system.

\section{Abbreviations}

BBB: blood-brain barrier; BDNF: brain-derived neurotrophic factor; CBF: cortical blood flow; CUMS: chronic unpredictable mild stress; FLU: fluoxetine hydrochloride; IHC: immunohistochemistry; IOD: integral optical density; KJ: kaixinjieyu; LBCCA: ligation of bilateral common carotid arteries; MMP: matrix metalloproteinase; NVU: neurovascular unit; OFT: openfield test; PAI-1: plasminogen activator inhibitor-1; SPT: sucrose preference test; t-PA: tissue plasminogen activator; TrkB: tropomyosin receptor kinase B; VD: vascular depression; ZO-1: zona occludens protein-1.

\section{Competing interests}

The authors declare that they have no competing interests.

\section{Authors' contributions}

Conceived and designed the experiments: SH, JP; Performed the experiments: $J H, X L, Y W, Y Z, D L$ and JZ; Performed sample preparation and compositional analysis: JW, HC and QL; Analyzed the data: JP, XL, JW and SH; Contributed reagents/materials/analysis tools: $\mathrm{XL}$ and $\mathrm{WC}$; Wrote the paper: JP, SH, XL and JW. All authors have read and approved the final manuscript.

\section{Acknowledgement}

This study was supported by the National Natural Sciences Foundation of China (grant no. 81072801), Beijing Municipal Science and Technology Program "Shi Bing Shi Yao" Research Projects (grant no. Z141100002214014) and China Academy of Chinese Medical Sciences Basic Scientific Research and Operating Projects (grant no. ZZ0708076).

\section{Author details}

'Guang'anmen Hospital, China Academy of Chinese Medical Sciences, Beijing 100053, China. ${ }^{2}$ Huangpi District Hospital of Traditional Chinese Medicine, Wuhan, Hubei 430300, China.

Received: 16 February 2015 Accepted: 7 August 2015

Published online: 19 August 2015

\section{References}

1. Taylor WD, Aizenstein HJ, Alexopoulos GS. The vascular depression hypothesis: mechanisms linking vascular disease with depression. Mol Psychiatry. 2013;18(9):963-74.

2. Sneed JR, Rindskopf D, Steffens DC, Krishnan KR, Roose SP. The vascular depression subtype: evidence of internal validity. Biol Psychiatry. 2008;64(6):491-7.

3. Gonzalez HM, Tarraf W, Whitfield K, Gallo JJ. Vascular depression prevalence and epidemiology in the United States. J Psychiatr Res. 2012;46(4):456-61. 
4. Culang-Reinlieb ME, Johnert LC, Brickman AM, Steffens DC, Garcon E, Sneed JR. MRI-defined vascular depression: a review of the construct. Int J Geriatr Psychiatry. 2011;26(11):1101-8

5. Sneed JR, Culang-Reinlieb ME. The vascular depression hypothesis: an update. Am J Geriatr Psychiatry. 2011;19(2):99-103

6. van Praag HM. Can stress cause depression? World J Biol Psychiatry. 2005;6 Suppl 2:5-22.

7. Bella R, Ferri R, Cantone M, Pennisi M, Lanza G, Malaguarnera G, et al. Motor cortex excitability in vascular depression. Int J Psychophysiol. 2011;82(3):248-53.

8. Brunoni AR, Bensenor IM, Alves TC. Therapeutic interventions for vascular depression: a systematic review. Rev Bras Psiquiatr. 2011;33(4):400-9.

9. Iosifescu DV, Renshaw PF, Lyoo IK, Lee HK, Perlis RH, Papakostas Gl, et al. Brain white-matter hyperintensities and treatment outcome in major depressive disorder. Br J Psychiatry. 2006;188:180-5.

10. Taylor W, Kamil K, Zheen Z, Steffens D, MacFall J. Cingulum bundle white matter lesions influence antidepressant response in late-life depression: Apilotstudy. J Affect Disord. 2014;162:8-11.

11. losifescu DV, Clementi-Craven N, Fraguas R, Papakostas Gl, Petersen T, Alpert JE, et al. Cardiovascular risk factors may moderate pharmacological treatment effects in major depressive disorder. Psychosom Med. 2005;67(5):703-6.

12. Sheline YI, Pieper CF, Barch DM, Welsh-Bohmer K, McKinstry RC, MacFall $J R$, et al. Support for the vascular depression hypothesis in late-life depression: results of a 2-site, prospective, antidepressant treatment trial. Arch Gen Psychiatry. 2010;67(3):277-85.

13. Duman RS, Monteggia LM. A neurotrophic model for stress-related mood disorders. Biol Psychiatry. 2006;59(12):1116-27.

14. Breuillaud L, Rossetti C, Meylan EM, Merinat C, Halfon O, Magistretti PJ, et al. Deletion of CREB-regulated transcription coactivator 1 induces pathological aggression, depression-related behaviors, and neuroplasticity genes dysregulation in mice. Biol Psychiatry. 2012;72(7):528-36.

15. Castren $\mathrm{E}$, Rantamaki $\mathrm{T}$. The role of BDNF and its receptors in depression and antidepressant drug action: Reactivation of developmental plasticity. Dev Neurobiol. 2010;70(5):289-97.

16. Gudmundsson P, Skoog I, Waern M, Blennow K, Palsson S, Rosengren L, et al. The relationship between cerebrospinal fluid biomarkers and depression in elderly women. Am J Geriatr Psychiatry. 2007;15(10):832-8.

17. Najjar S, Pearlman DM, Devinsky O, Najjar A, Zagzag D. Neurovascular unit dysfunction with blood-brain barrier hyperpermeability contributes to major depressive disorder: a review of clinical and experimental evidence

J Neuroinflammation. 2013;10:142.

18. Zlokovic BV. Neurodegeneration and the neurovascular unit. Nat Med. 2010;16(12):1370-1.

19. Huang SJ, Zhang $X H$, Wang $Y Y$, Pan JH, Cui HM, Fang SP, et al. Effects of Kaixin Jieyu Decoction on behavior, monoamine neurotransmitter levels, and serotonin receptor subtype expression in the brain of a rat depression model. Chin J Integr Med. 2014;20(4):280-5.

20. Zhang $X H$, Huang SJ, Wang YY, Zhang Y, Pan JH, Zheng J, et al. Effects of Kaixin Jieyu Decoction on behavior and glial fibrillary acidic protein expression in cerebral hippocampus of a rat vascular depression model. Chin J Integr Med. 2015;21(3):223-8.

21. Hritcu L, Gorgan LD. Intranigral lipopolysaccharide induced anxiety and depression by altered BDNF mRNA expression in rat hippocampus. Prog Neuropsychopharmacol Biol Psychiatry. 2014;51:126-32.

22. Kosel M, Brockmann H, Frick C, Zobel A, Schlaepfer TE. Chronic vagus nerve stimulation for treatment-resistant depression increases regional cerebral blood flow in the dorsolateral prefrontal cortex. Psychiatry Res. 2011;191(3):153-9.

23. Liu X, Wang Z, Wang P, Yu B, Liu Y, Xue Y. Green tea polyphenols alleviate early BBB damage during experimental focal cerebral ischemia through regulating tight junctions and PKCalpha signaling. BMC Complement Altern Med. 2013;13:187.

24. Yatomi Y, Tanaka R, Shimura H, Miyamoto N, Yamashiro K, Takanashi M, et al. Chronic brain ischemia induces the expression of glial glutamate transporter EAAT2 in subcortical white matter. Neuroscience. 2013;244:113-21.

25. Rinwa P, Kumar A, Garg S. Suppression of neuroinflammatory and apoptotic signaling cascade by curcumin alone and in combination with piperine in rat model of olfactory bulbectomy induced depression. PLoS One. 2013:8(4), e61052.

26. Isingrini E, Belzung C, D'Audiffret A, Camus V. Early and late-onset effect of chronic stress on vascular function in mice: a possible model of the impact of depression on vascular disease in aging. Am J Geriatr Psychiatry. 2011;19(4):335-46.

27. Pan JH, Wang YY, Huang SJ, Mao YR, Chen Z, Zheng J, et al. Establishment of Rat Model of Vascular Depression. Shou Du Yi Ke Da Xue Xue Bao. 2007;28(6):760-2.

28. Choy M, Ganesan V, Thomas DL, Thornton JS, Proctor E, King MD, et al. The chronic vascular and haemodynamic response after permanent bilateral common carotid occlusion in newborn and adult rats. J Cereb Blood Flow Metab. 2006;26(8):1066-75

29. Otori T, Katsumata T, Muramatsu H, Kashiwagi F, Katayama $Y$, Terashi A. Long-term measurement of cerebral blood flow and metabolism in a rat chronic hypoperfusion model. Clin Exp Pharmacol Physiol. 2003:30(4):266-72

30. Youdim KA, Dobbie MS, Kuhnle G, Proteggente AR, Abbott NJ, RiceEvans C. Interaction between flavonoids and the blood-brain barrier: in vitro studies. J Neurochem. 2003;85(1):180-92.

31. Hwang SL, Shih PH, Yen GC. Neuroprotective effects of citrus flavonoids. J Agric Food Chem. 2012;60(4):877-85.

32. Ye J, Lin $H_{1}$ Mu J, Cui $X$, Ying $H$, Lin $M$, et al. Effect of basic fibroblast growth factor on hippocampal cholinergic neurons in a rodent model of ischaemic encephalopathy. Basic Clin Pharmacol Toxicol. 2010;107(6):931-9.

33. Shetty AK, Mishra V, Kodali M, Hattiangady B. Blood brain barrier dysfunction and delayed neurological deficits in mild traumatic brain injury induced by blast shock waves. Front Cell Neurosci. 2014;8:232.

34. Takeda S, Sato N, Morishita R. Systemic inflammation, blood-brain barrier vulnerability and cognitive/non-cognitive symptoms in Alzheimer disease: relevance to pathogenesis and therapy. Front Aging Neurosci. 2014;6:171.

35. Sato $Y$, Chin $Y$, Kato T, Tanaka Y, Tozuka Y, Mase M, et al. White matter activated glial cells produce BDNF in a stroke model of monkeys. Neurosci Res. 2009;65(1):71-8

36. Yoshii A, Constantine-Paton M. Postsynaptic BDNF-TrkB signaling in synapse maturation, plasticity, and disease. Dev Neurobiol. 2010;70(5):304-22.

37. Neeley EW, Berger R, Koenig Jl, Leonard S. Prenatal stress differentially alters brain-derived neurotrophic factor expression and signaling across rat strains. Neuroscience. 2011;187:24-35.

38. Collen D. The plasminogen (fibrinolytic) system. Thromb Haemost. 1999:82(2):259-70

39. Salles FJ, Strickland S. Localization and regulation of the tissue plasminogen activator-plasmin system in the hippocampus. J Neurosci. 2002:22(6):2125-34.

40. Eskandari F, Mistry S, Martinez PE, Torvik S, Kotila C, Sebring N, et al. Younger, premenopausal women with major depressive disorder have more abdominal fat and increased serum levels of prothrombotic factors: implications for greater cardiovascular risk. Metabolism. 2005;54(7):918-24.

41. Tsai SJ, Hong CJ, Liou YJ, Yu YW, Chen TJ. Plasminogen activator inhibitor-1 gene is associated with major depression and antidepressant treatment response. Pharmacogenet Genomics. 2008;18(10):869-75.

42. Tsai SJ. The possible role of tissue-type plasminogen activator and the plasminogen system in the pathogenesis of major depression. Med Hypotheses. 2006;66(2):319-22.

43. Carrano A, Hoozemans JJ, van der Vies SM, Rozemuller AJ, van Horssen $J$, de Vries HE. Amyloid Beta induces oxidative stress-mediated bloodbrain barrier changes in capillary amyloid angiopathy. Antioxid Redox Signal. 2011;15(5):1167-78.

44. Zlokovic BV. The blood-brain barrier in health and chronic neurodegenerative disorders. Neuron. 2008;57(2):178-201.

45. Mishiro K, Ishiguro M, Suzuki Y, Tsuruma K, Shimazawa M, Hara H. A broadspectrum matrix metalloproteinase inhibitor prevents hemorrhagic complications induced by tissue plasminogen activator in mice. Neuroscience. 2012;205:39-48.

46. Shalev $H$, Serlin $Y$, Friedman A. Breaching the blood-brain barrier as a gate to psychiatric disorder. Cardiovasc Psychiatry Neurol. 2009;2009:278531

47. Lehner C, Gehwolf R, Tempfer H, Krizbai I, Hennig B, Bauer HC, et al. Oxidative stress and blood-brain barrier dysfunction under particular consideration of matrix metalloproteinases. Antioxid Redox Signal. 2011;15(5):1305-23. 
48. Nakaji K, Ihara M, Takahashi C, Itohara S, Noda M, Takahashi R, et al. Matrix metalloproteinase-2 plays a critical role in the pathogenesis of white matter lesions after chronic cerebral hypoperfusion in rodents. Stroke. 2006:37(11):2816-23.

49. Tai SH, Chen HY, Lee EJ, Chen TY, Lin HW, Hung YC, et al. Melatonin inhibits postischemic matrix metalloproteinase-9 (MMP-9) activation via dual modulation of plasminogen/plasmin system and endogenous MMP inhibitor in mice subjected to transient focal cerebral ischemia. J Pineal Res. 2010;49(4):332-41.

Submit your next manuscript to BioMed Central and take full advantage of:

- Convenient online submission

- Thorough peer review

- No space constraints or color figure charges

- Immediate publication on acceptance

- Inclusion in PubMed, CAS, Scopus and Google Scholar

- Research which is freely available for redistribution 